\title{
Vitamin D and health in adults in Australia and New Zealand: a position statement
}

Caryl A Nowson PhD, DipNutDiet, Chair of Nutrition and Ageing

John J McGrath AM, MB BS, MD, PhD Director $^{2}$

Peter R Ebeling MB BS, MD, Professor and Chair of the NorthWest Academic Centre, Western Section

(Assistant Dean) ${ }^{3}$

Anjali Haikerwal

BSc, MB BS, MPH Research Coordinator

Robin M Daly PhD,

Chair of Exercise and

Ageing

Kerrie M Sanders

BSc, GradDipDiet, PhD,

Associate Professor,

NorthWest Academi

Centre $^{3}$

Markus J Seibel MD, PhD,

Professor and Chair of

Endocrinology

Rebecca S Mason MB BS, PhD,

Professor and Head of

Physiology ${ }^{5}$

Working Group of the

Australian and New

Zealand Bone and Mineral

Society, Endocrine Society

of Australia and

Osteoporosis Australia

ICentre for Physical Activity

and Nutrition Research

Deakin University,

Melbourne, VIC

2 Queensland Centre for Mental Health Research

University of Queensland, Brisbane, QLD.

3 Department of Medicine University of Melbourne Melbourne, VIC.

4 Department of Medicine, Concord Clinical School,

ANZAC Research Institute,

University of Sydney,

Sydney, NSW.

5 Department of Physiology and Bosch Institute, University of Sydney, Sydney, NSW.

caryl.nowson@ deakin.edu.au

doi: 10.5694/mjall.10301

An abridged version of this article appeared in the printed journal itamin D status has emerged as a significant public health issue in Australia and New Zealand. An estimated $31 \%$ of adults in Australia have inadequate vitamin D status (serum 25-hydroxyvitamin D [25-OHD] level $<50 \mathrm{nmol} / \mathrm{L}$ ), increasing to more than $50 \%$ in women during winter-spring and in people residing in southern states. ${ }^{1}$ This field of research is fastmoving, and it is timely to re-examine past recommendations ${ }^{2}$ in light of the increasing number of medical conditions associated with low vitamin D status, and indications that higher levels of circulating serum 25OHD may be required for optimal health. This article provides updated guidance to clinicians and health professionals on the role of vitamin D in health for adults. The guideline development process is outlined in Box 1 .

The generic term "vitamin $\mathrm{D}$ " is generally applied to two molecules: cholecalciferol and ergocalciferol. Cholecalciferol (vitamin $\mathrm{D}_{3}$ ) is formed through the action of ultraviolet B (UVB) radiation (wavelength, 290-315 nm) on 7-dehydrocholesterol in the skin. This process is the major determinant of vitamin D status, as most adults are unlikely to obtain more than $5 \%-10 \%$ of their vitamin D requirement from dietary sources. Cholecalciferol is also the major form of supplemental vitamin D currently available in Australasia. The other form of vitamin D, ergocalciferol (vitamin $\mathrm{D}_{2}$ ), is produced by UV irradiation of the plant sterol ergosterol. Few vitamin D supplements now contain this form. Both forms of vitamin $\mathrm{D}$ are transported to the liver and metabolised to 25-OHD. This is the major circulating form and the metabolite routinely used to assess overall vitamin D status. It is also likely to be the metabolite responsible for hypercalcaemia when vitamin $\mathrm{D}$ is given in excess. ${ }^{3}$

Further hydroxylation occurs in the kidney to form the biologically active 1,25-dihydroxyvitamin D (1,25$\left.(\mathrm{OH})_{2} \mathrm{D}\right)$, also known as calcitriol. This compound promotes absorption of calcium and phosphate from the gut, contributes to extracellular calcium and phosphate homeostasis directly and through an interaction with parathyroid hormone (PTH), facilitates mineralisation of the skeleton, and is important for muscle function. ${ }^{4}$ In addition, almost every nucleated cell expresses the vitamin $\mathrm{D}$ receptor, and many extrarenal tissues have the capacity to make $1,25-(\mathrm{OH})_{2} \mathrm{D}$. Thus, vitamin $\mathrm{D}$ can operate via classical endocrine pathways (renal synthesis of $1,25-(\mathrm{OH})_{2} \mathrm{D}$ under the control of calcium concentration via PTH, or phosphate, with secretion into the bloodstream to increase intestinal calcium absorption), as well as through autocrine and paracrine pathways involving local synthesis and actions.
- The prevalence of vitamin D deficiency varies, with the groups at greatest risk including housebound, community-dwelling older and/or disabled people, those in residential care, dark-skinned people (particularly those modestly dressed), and other people who regularly avoid sun exposure or work indoors.

- Most adults are unlikely to obtain more than 5\%-10\% of their vitamin $D$ requirement from dietary sources. The main source of vitamin $D$ for people residing in Australia and New Zealand is exposure to sunlight.

- A serum 25-hydroxyvitamin D (25-OHD) level of $\geqslant 50 \mathrm{nmol} / \mathrm{L}$ at the end of winter $(10-20 \mathrm{nmol} / \mathrm{L}$ higher at the end of summer, to allow for seasonal decrease) is required for optimal musculoskeletal health.

- Although it is likely that higher serum 25-OHD levels play a role in the prevention of some disease states, there is insufficient evidence from randomised controlled trials to recommend higher targets.

- For moderately fair-skinned people, a walk with arms exposed for 6-7 minutes mid morning or mid afternoon in summer, and with as much bare skin exposed as feasible for 7-40 minutes (depending on latitude) at noon in winter, on most days, is likely to be helpful in maintaining adequate vitamin $\mathrm{D}$ levels in the body.

- When sun exposure is minimal, vitamin $D$ intake from dietary sources and supplementation of at least $600 \mathrm{IU}$ $(15 \mu \mathrm{g})$ per day for people aged $\leqslant 70$ years and $800 \mathrm{IU}$ $(20 \mu \mathrm{g})$ per day for those aged $>70$ years is recommended. People in high-risk groups may require higher doses.

- There is good evidence that vitamin D plus calcium supplementation effectively reduces fractures and falls in older men and women.

\section{Sunlight as a source of vitamin D}

For most people, the main source of vitamin D is skin exposure to sunlight. The minimal erythemal dose (MED) is the amount of UV radiation exposure that just causes faint redness of the skin (erythema). At low wavelengths, in the UVB range, the action spectrum for production of erythema is similar to that for production of vitamin D. However, erythema, but not vitamin D, can also be produced by higher-wavelength UVA radiation. This limits the usefulness of MED as an index of vitamin D dose. ${ }^{5}$ Nevertheless, there are experimental data indicating that exposure of around $15 \%$ of the body surface (arms and hands or equivalent) to one-third of an MED near the middle of the day will result in the production of about $1000 \mathrm{IU}(25 \mu \mathrm{g})$ of vitamin D. Achieving this exposure on most days should generally, 


\section{Position statement development process}

This position statement was developed by a Working Group (joint Chairs, CN and R M) commissioned by the Australian and New Zealand Bone and Mineral Society (ANZBMS) and Osteoporosis Australia (OA). All members of the Working Group have published extensively in the field of vitamin D. Specific expertise includes: nutrition (CN, KS), brain (JM), endocrinology (PE, A H, R M), exercise (RD), measurement (MS) and sunlight exposure (RM).

The Working Group prepared an initial evidence-based draft statement that was circulated to senior colleagues in clinical bone research in Australia for comment. The statement was subsequently modified, and all members of the ANZBMS and Endocrine Society of Australia (ESA) were notified by email that a draft statement had been posted on the ANZBMS website for widespread comment and feedback. Suggested revisions were incorporated with consensus from the Working Group. The medical and scientific affairs committees of the ANZBMS, OA and ESA reviewed the final manuscript. This edited version of the full position statement has been reviewed by all members of the Working Group and senior representatives of ANZBMS, OA and ESA.

though not always, be sufficient to maintain vitamin D levels in the body. 5,6

The amount of sun exposure required to produce onethird of an MED depends on several factors (Box 2). Less vitamin $\mathrm{D}$ is synthesised in winter, particularly at latitudes further from the equator. There is minimal transmission of UVB radiation through normal window glass. Although sunscreens also markedly reduce transmission in the UVB range, these are often inadequately applied and may have little impact on vitamin D status. ${ }^{7}$ Lack of any skin exposure to sunlight, through confinement indoors or from clothing, is a more common issue. Short UV radiation exposures (of a few minutes) may be more efficient at producing vitamin $\mathrm{D}$, as prolonged exposure to UV radiation results in the production of sterols that have little effect on mineral metabolism. ${ }^{4}$

For people with moderately fair skin, adequate vitamin D levels are likely to be maintained in summer by a walk outside with arms exposed for 6-7 minutes mid morning or mid afternoon, on most days. In winter the task is more difficult but, depending on latitude, walking outside at lunchtime for 7-40 minutes, with as much bare skin exposed as feasible, on most days, is likely to be helpful, although at very southern latitudes, relatively little vitamin $\mathrm{D}$ would be formed (Box 2). ${ }^{5}$ Care needs to be taken by people in the far north of Australia where the UV intensity remains moderate to high throughout the year. Given the high incidence of skin cancer in Australasia, sunscreens and other UV radiation avoidance measures should be used if exposure is likely to be prolonged when the UV index is 3 or above and/or there is a risk of skin damage, even for people with vitamin D deficiency. Some people are at particularly high risk of skin cancer, including those with a past history of skin cancer and those who are immunosuppressed. Such people need more rigorous sun protection and should discuss with their medical practitioner whether supplements might be more appropriate than sun exposure to maintain vitamin D levels.

\section{Groups at high risk of vitamin D deficiency}

Adult groups at high risk of vitamin D deficiency are shown in Box 3. Although older people are an at-risk group for developing vitamin D deficiency, because they have less substrate (7-dehydrocholesterol in the skin) and lower production rates of vitamin D from high levels of UV
2 Minutes of sun exposure needed for people with moderately fair skin to achieve about one-third of a minimal erythemal dose (MED)*

Time of year and day

\begin{tabular}{lcc}
\cline { 2 - 3 } Region and city ${ }^{\dagger}$ & $\begin{array}{c}\text { December-January, } \\
\text { 10 am or } 2 \text { pm }^{\ddagger}\end{array}$ & $\begin{array}{c}\text { July-August, } \\
12 ~ p m ~\end{array}$ \\
\hline Northern & $6-7$ & 7 \\
Cairns & $5-7$ & 7 \\
Townsville & & 11 \\
Central & $6-7$ & 15 \\
Brisbane & $5-6$ & 16 \\
Perth & & 19 \\
Southern & $6-8$ & 25 \\
Sydney & $5-7$ & 29 \\
Adelaide & $6-8$ & \\
Melbourne & $7-9$ & 24 \\
Hobart & $6-8$ & $40^{5}$ \\
New Zealand & $6-9$ & 16 \\
Auckland & & \\
Christchurch & 5
\end{tabular}

* Based on $1 \mathrm{MED}=200 \mathrm{~J} / \mathrm{m}^{2}$ effective or 2 standard erythemal doses for people with type I or II (sensitive) skin. MED is not an index for vitamin D dose, except when there are high levels of ultraviolet B (UVB) radiation (see text). Times for people with highly pigmented skin would be 3-6 times longer. ${ }^{4,7}$

† Data for Australian cities ${ }^{8}$ use measured averages of MED/hour over the 2 months shown, for a minimum of 5 years during the period 1996-2003, except for Hobart, which is based on data from 1 year. Times for New Zealand are calculated from UV data averaged over a 2-year period between 2002 and 2004, provided by the National Institute of Water and Atmospheric Research. Current data are substantially unchanged from that period (Peter Gies, Senior Research Scientist, Non-Ionizing Section, Radiation Health Services Branch, Australian Radiation Protection and Nuclear Safety Agency, personal communication, Oct 2010).

$\ddagger 11$ am or $3 \mathrm{pm}$ during daylight saving time.

$\S$ At the latitude of Christchurch, very little vitamin D would form due to very small amounts of low-wavelength UVB radiation. ${ }^{5}$

radiation exposure, ${ }^{13}$ they synthesise similar amounts of vitamin $\mathrm{D}$ as younger people at normal levels of UV radiation exposure. ${ }^{14} \mathrm{~A}$ major reason for vitamin $\mathrm{D}$ deficiency in older people is limited sun exposure. ${ }^{9}$

Vitamin D synthesis is reduced in those who have dark skin due to the presence of melanin, which absorbs UV radiation. ${ }^{7}$ People with dark skin are likely to need sun exposures 3-6 times longer than the times shown in Box 2. Vitamin D synthesis is also reduced by clothing, 7,15,16 and people who wear covering clothing for cultural or religious reasons are an at-risk group. The sun avoidance behaviour of fair-skinned people increases their risk of vitamin D deficiency. ${ }^{11,17}$ Reduced sun exposure is also likely to contribute to increased risk of vitamin D deficiency in people with chronic illness and those confined indoors. There is some evidence that sun exposure and vitamin D status may have separate roles in the development of disease. ${ }^{18}$

\section{Dietary sources of vitamin D}

Vitamin $\mathrm{D}_{3}$ is found naturally in small quantities in a few foods, such as wild-caught fatty fish (eg, North Sea salmon, herring, mackerel). Liver, eggs and fortified foods such as margarine and some low-fat milk products also contain very small amounts of vitamin $\mathrm{D}_{3}$. In Australia, there is one specially supplemented milk product with 


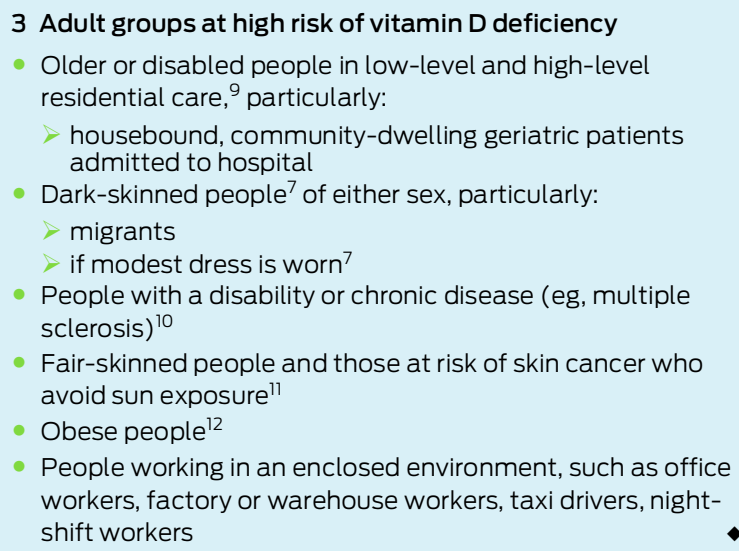

$200 \mathrm{IU}(5 \mu \mathrm{g})$ of vitamin D per $250 \mathrm{~mL}$ serve, and some mushrooms that have been exposed to UV radiation provide $800 \mathrm{IU}(20 \mu \mathrm{g})$ of vitamin $\mathrm{D}_{2}$ per $100 \mathrm{~g} .{ }^{4}$ However, for most people, dietary vitamin $\mathrm{D}$ intake is limited.

Although accurate, comprehensive data on the vitamin D content of foods in Australasia are not available, vitamin $\mathrm{D}$ intake from dietary sources is likely to be insufficient to meet requirements, as the average estimated daily dietary intake for adults is only between 80 and $120 \mathrm{IU}(2-3 \mu \mathrm{g}){ }^{19}$ This is considerably lower than in other countries (eg, Canada and the United States, where average intake ranges between 120 and $240 \mathrm{IU}$ [3-6 $\mu \mathrm{g}$ ] per day) where more extensive vitamin D fortification of the food supply is mandated or permitted. ${ }^{20}$ It is acknowledged that the current (2006) guidelines for recommended dietary intakes (ie, adequate intakes) of vitamin D in Australia and New Zealand $^{21}$ are out of date. The recently revised recommended daily allowances (RDAs) for vitamin D in the US are $600 \mathrm{IU}(15 \mu \mathrm{g})$ for people aged $1-70$ years and $800 \mathrm{IU}$ $(20 \mu \mathrm{g})$ for those aged $\geqslant 71$ years, with an upper limit (that includes a generous safety factor) of $4000 \mathrm{IU}(100 \mu \mathrm{g}){ }^{22}$

\section{Effect of vitamin D on mineral metabolism, bone health and muscle function}

The most clearly established effects of vitamin D are to maintain calcium and phosphate homeostasis, and to optimise bone health and muscle function. ${ }^{23-25}$ The hormonal form, $1,25-(\mathrm{OH})_{2} \mathrm{D}$, increases active intestinal calcium (and phosphate) absorption, which helps offset obligatory calcium losses from the kidneys, gut and skin. Calcium concentrations in blood are maintained within narrow limits, so if inadequate calcium is absorbed from dietary sources, bone resorption increases under the influence of PTH, to maintain circulating calcium levels. Severe vitamin D deficiency causes impaired bone mineralisation, resulting in rickets in children and osteomalacia in adults. There is Level II evidence that optimal mineral metabolism, bone density and muscle function is achieved at serum $25-\mathrm{OHD}$ concentrations of $50-60 \mathrm{nmol} / \mathrm{L}^{23-26}$ with no consistent evidence that higher levels are beneficial. Although most of these studies have been in older people, there is some evidence of improvement in bone mineral content from vitamin D supplementation in children and adolescents aged between 1 month and 20 years with low vitamin D levels $(<35 \mathrm{nmol} / \mathrm{L}) .{ }^{27}$ Further, a recent histomorphometric study of 675 German adults showed increased osteoid (unmineralised bone matrix) in some people with $25-\mathrm{OHD}$ concentrations $<75 \mathrm{nmol} / \mathrm{L}$, suggesting that this may be an appropriate cut-off for optimal bone health. ${ }^{28}$

Vitamin D deficiency is an independent predictor of falls in older people, and circulating 25-OHD levels <60$75 \mathrm{nmol} / \mathrm{L}$ have been associated with lower-extremity muscle weakness and impaired balance, and accelerated losses in muscle mass, strength and physical function. ${ }^{25,29}$ A recent meta-analysis indicated that a minimum serum $25-\mathrm{OHD}$ level of $60 \mathrm{nmol} / \mathrm{L}$ is required to effectively reduce the rate of falls, ${ }^{30}$ although this analysis has been disputed..$^{22}$ Most Level I evidence indicates that vitamin D (at daily doses of $>800 \mathrm{IU}$ [20 $\mu \mathrm{g}]$ ) needs to be combined with adequate calcium (> $1000 \mathrm{mg}$ per day), rather than vitamin $\mathrm{D}$ alone, to reduce the risk of falls and fractures; although there may be benefits with single therapies. ${ }^{30-34}$ Therefore, older people would be recommended to consume adequate (1000-1300 mg per day) but not excessive dietary intakes of calcium, together with maintaining adequate vitamin D status (within the 25-OHD range 50-60 nmol/L, allowing for seasonal variation), to reduce risk of falls and fracture. This recommendation is consistent with the recent review conducted by the US Institute of Medicine that recommends a minimum serum level of $50 \mathrm{nmol} / \mathrm{L}$, which can be achieved by meeting the RDA for vitamin D. ${ }^{22,35}$

\section{Relationship of serum 25-OHD levels to disease}

A wide range of diseases have been associated with low levels of circulating serum $25-\mathrm{OHD},{ }^{4,13}$ including autoimmune diseases, ${ }^{36,37}$ cardiovascular and metabolic diseases, ${ }^{4,38-40}$ some cancers, ${ }^{41,42}$ microbial and respiratory diseases, ${ }^{4,43-45}$ and some neurological and mental health conditions $^{46-48}$ including schizophrenia, ${ }^{49}$ as well as allcause and cardiovascular mortality ${ }^{50,51}$ (Box 4). Most of these studies were observational and did not adjust for important confounders. While there are studies in animal models that support the epidemiological evidence, and plausible mechanisms to explain the effects of vitamin D, there are very few randomised controlled trials (RCTs), most of which have marked limitations, on which to base recommendations. ${ }^{39,41,44}$ Accordingly, proposals that recommend serum 25-OHD levels of $75-80 \mathrm{nmol} / \mathrm{L}$ or higher ${ }^{56}$ are not supported by a significant amount of data from RCTs. ${ }^{22}$

Other epidemiological studies have recently provided Level III evidence of U-shaped exposure-risk relationships between serum 25-OHD levels and disease outcomes (ie, increased risk at both low $[<30 \mathrm{nmol} / \mathrm{L}]$ and high $[>75$ or $>125 \mathrm{nmol} / \mathrm{L}]$ concentrations) for mortality, ${ }^{57,58}$ schizophrenia, ${ }^{49}$ prostate cancer, ${ }^{59}$ and frailty in women. ${ }^{60}$ These U-shaped curves may in part reflect a mixture of common genetic variants, ${ }^{61}$ but further RCTs are needed. 
4 Key evidence that low serum 25-hydroxyvitamin D levels are associated with disease*

Level I

- Vitamin D plus calcium supplementation reduces risk of falls $^{30,52}$ and fractures $22,31-34$

- All-cause mortality ${ }^{51}$

Level II

- Insulin resistance ${ }^{39,40}$

Level III

- Cancer $^{41}$ (Level III-1)

Influenza type $A^{44}$ (Level III-1)

- Autoimmune disorders, ${ }^{37}$ rheumatoid arthritis, ${ }^{53}$ type 1 diabetes, ${ }^{36}$ multiple sclerosis, ${ }^{10}$ cardiovascular disease, $, 38,54$ schizophrenia, ${ }^{49}$ cognitive decline,${ }^{46}$ depression, ${ }^{48}$ active tuberculosis, ${ }^{43}$ increased susceptibility to infection, ${ }^{45}$ cancer (colon, breast), ${ }^{42}$ neurological conditions ${ }^{47}$ (Level III-2)

* Based on National Health and Medical Research Council levels of evidence. ${ }^{55}$

\section{Other factors affecting vitamin D status}

Vitamin D enters adipose tissue and may not be readily released, unless there is fat breakdown, so obesity results in lower vitamin D levels after receipt of oral or cutaneously synthesised vitamin D. ${ }^{12}$ Physical activity is a predictor of vitamin D status, ${ }^{62}$ which could be due to alteration in the storage and mobilisation of vitamin D in fat ${ }^{63}$ or to greater exposure to sunlight when exercising. Polymorphisms in the genes for vitamin D-binding protein, 7dehydrocholesterol reductase (which affects the amount of substrate 7-dehydrocholesterol in skin) and 25-hydroxylase may contribute as much to variation in 25-OHD levels as the summer-winter difference. ${ }^{61,64}$ The half-life of 25 $\mathrm{OHD}$ is long and, for reasons that are not entirely known, varies between 15 and 50 days. ${ }^{65}$ Some medications, such as cytochrome P450 enzyme inducers, including some anticonvulsants, accelerate degradation of vitamin D compounds. ${ }^{66}$

One important factor is calcium intake, with low intakes of calcium or high levels of PTH (either primary or secondary) linked to accelerated degradation of 25-OHD and a shorter half-life. ${ }^{67}$ In contrast, increased dietary calcium intake leads to higher 25-OHD concentrations. ${ }^{68,69}$ Low calcium absorption may be the reason why people with malabsorption, or who undergo gastrectomy or related procedures, ${ }^{69}$ have reduced $25-\mathrm{OHD}$ levels, as there is no evidence for clinically significant enterohepatic circulation of vitamin D compounds. ${ }^{70}$

\section{Toxicity}

The main concerns with excessive vitamin D levels are hypercalciuria and hypercalcaemia. Vitamin D toxicity can be caused by excess oral intake through supplementation, but not by prolonged exposure of the skin to sunlight, which produces 25-OHD values in the range 150 $200 \mathrm{nmol} / \mathrm{L}$. ${ }^{4,5,71}$ Hypercalcaemia is not seen until serum 25-OHD levels reach $220 \mathrm{nmol} / \mathrm{L}$ and is generally not reported until levels reach $500 \mathrm{nmol} / \mathrm{L}^{71}$ There is no evidence of toxicity, based on blood calcium concentrations, at vitamin D doses up to $5000 \mathrm{IU}$ per day or $50000 \mathrm{IU}$ per month. $^{72-74}$
However, adverse effects can probably no longer be defined solely by hypercalcaemia, as a large RCT in older Australian women found that a single annual dose of $500000 \mathrm{IU}$ vitamin $\mathrm{D}_{3}$ for $3-5$ years resulted in a $15 \%$ increase in falls and $26 \%$ increase in fractures. ${ }^{75}$ The increased risk of falls was pronounced in the first 3 months after taking the dose, and fracture risk also tended to be higher during this 3-month post-dose period, when serum 25-OHD levels would have been highest. Annual megadose vitamin D is thus not recommended, although a 5year community study providing $100000 \mathrm{IU}(2500 \mu \mathrm{g})$ of oral vitamin $\mathrm{D}_{3}$ every 4 months to older people did show benefits for fracture reduction. ${ }^{76}$ Furthermore, intramuscular administration of vitamin D (100 000 or 150000 IU) may be appropriate in patients with malabsorption, although intramuscular preparations are not readily available in Australia. Administration of vitamin D is contraindicated in most cases of hypercalciuria or hypercalcaemia. Vitamin $\mathrm{D}$ treatment is not contraindicated in patients with primary hyperparathyroidism and vitamin D deficiency. ${ }^{77}$ Cod liver oil, which can be used for vitamin D supplementation, also contains vitamin $\mathrm{A}$, which can be toxic at high doses.

\section{Serum 25-OHD status and target values}

Based on our review of the available evidence, vitamin D status can be defined according to the following levels of serum 25-OHD:

- Vitamin D adequacy: $\geqslant 50 \mathrm{nmol} / \mathrm{L}$ at the end of winter (level may need to be $10-20 \mathrm{nmol} / \mathrm{L}$ higher at the end of summer, to allow for seasonal decrease).

- Mild vitamin D deficiency: 30-49 nmol/L

- Moderate vitamin deficiency: $12.5-29 \mathrm{nmol} / \mathrm{L}$

- Severe vitamin D deficiency: < $12.5 \mathrm{nmol} / \mathrm{L}$

On the basis of the evidence discussed above, a target level for vitamin D adequacy for mineral homeostasis, bone health and muscle function would seem to be $>50$ or $60 \mathrm{nmol} / \mathrm{L},{ }^{22,24}$ although optimal values, even for bone and muscle health, are not clear. Ideally, the target value should allow for a decrease in vitamin $\mathrm{D}$ levels during winter. ${ }^{17} \mathrm{An}$ international consensus statement recently agreed on a 25-OHD serum concentration range between 50 and $62.5 \mathrm{nmol} / \mathrm{L}(20-25 \mathrm{ng} / \mathrm{mL})$ to prevent adverse musculoskeletal outcomes, including falls and fractures. ${ }^{78}$ The target serum level for prevention of other diseases is not clear but may be higher, in the range of 75-80 nmol/L (30$32 \mathrm{ng} / \mathrm{mL}$ ). However, there is currently limited high-level evidence to support these higher 25-OHD serum levels. ${ }^{56}$

Clinicians, researchers and policymakers should be aware of the imprecision of current 25-OHD testing, and exercise caution when interpreting results in clinical practice. Although the performance of radioimmunoassay and enzyme-linked assays is acceptable, the bias and imprecision of many automated methods may be problematic at the lower, clinically and analytically important range $(<50 \mathrm{nmol} /$ L) of the assay. While adoption and alignment of assays to the National Institute of Standards and Technology reference material should reduce bias, ${ }^{79}$ imprecision will remain problematic. Consequently, some laboratories are using more exacting methods of analysis, such as liquid chromatography-tandem mass spectrometry. ${ }^{79}$ All Australian and 
New Zealand laboratories offering 25-OHD testing are required to be enrolled in external proficiency programs (such as the Vitamin D External Quality Assessment Scheme [DEQAS]), which allow each laboratory to monitor its performance compared with its peers.

\section{Supplemental vitamin D doses required to achieve targets}

Some studies have shown that with supplemental vitamin $\mathrm{D}_{3}$, 25-OHD levels reach a plateau at about 8 weeks, after rising by, on average, about $0.7 \mathrm{nmol} / \mathrm{L}$ for each $40 \mathrm{IU}$ $(1 \mu \mathrm{g})$ per day of supplemental vitamin $\mathrm{D}_{3}$ (ie, an increase of about $17 \mathrm{nmol} / \mathrm{L}$ for each $1000 \mathrm{IU}$ [25 $\mu \mathrm{g}$ ] per day). ${ }^{73,80}$ However, at any given dose there is considerable individual variation in the plateau level achieved. Although the increment is negatively correlated to the baseline 25-OHD concentration, it is not significantly affected by race, sex or age. $^{80,81}$ Obesity, however, is associated with lower levels of 25-OHD and a reduced dose response to oral vitamin D or UV radiation. ${ }^{7,12}$ As it may take up to $2-5$ months for serum levels of $25-\mathrm{OHD}$ to plateau, ${ }^{80,82}$ retesting should not take place before 3 months.

There appears to be little difference in 25-OHD values whether the total amount of vitamin $\mathrm{D}$ is given as a daily, weekly or monthly dose, with no clear indication that one dosing schedule is more effective than another. Intermittent dosing may be more convenient in some settings, such as nursing homes, ${ }^{83}$ and may also achieve better long-term compliance. ${ }^{73}$ There is conflicting evidence about whether vitamin $\mathrm{D}_{3}$ is more effective than vitamin $\mathrm{D}_{2}$ in raising 25 -OHD levels, ${ }^{84,85}$ but virtually all oral vitamin D supplements available in Australia and New Zealand are vitamin $D_{3}$. There are currently no generally available, Therapeutic Goods Administration-approved parenteral preparations of vitamin D, although these might be helpful where ability to swallow, malabsorption or compliance are problems.

Recommendations for assessment and management of vitamin $\mathrm{D}$ deficiency are shown in Box 5 . To treat moderate to severe deficiency, it would be reasonable to use 3000-5000 IU (75-125 $\mu \mathrm{g})$ of vitamin D per day for at least 6-12 weeks, although there are no long-term safety data for these doses. This will usually return serum 25OHD levels to the target range, although smaller daily doses of 2000 IU might be expected to increase 25-OHD levels by $34 \mathrm{nmol} / \mathrm{L}$, as noted earlier. As there is such an individual variation of response to vitamin D supplementation, 25-OHD levels should be checked after 3 months. If adequate levels are not achieved, consideration should be given to possible underlying gastrointestinal disorders, such as coeliac disease. Most patients whose 25OHD levels have normalised will need ongoing treatment at a maintenance dose of around 1000-2000 IU (25$50 \mu \mathrm{g})$ per day or equivalent.

For adults in disadvantaged communities at high risk of vitamin D deficiency, such as dark-skinned migrants from low socioeconomic backgrounds, a strong case could be made to routinely provide vitamin D supplements, at the same dose used to treat moderate to severe deficiency, as early as possible, without initially measur-
5 Recommendations for assessment and management of vitamin $D$ deficiency states

\section{High-risk groups}

- Screening blood test for 25-hydroxyvitamin D (25-OHD) level performed by a reputable laboratory participating in the Vitamin D External Quality Assessment Scheme (DEQAS) proficiency program, followed by appropriate vitamin supplementation

- Supplementation without initial screening may be appropriate in some high-risk groups (eg, dark-skinned migrants, people in residential care establishments)

Minimum sun exposure to prevent deficiency

- For moderately fair-skinned people, a walk with arms exposed for 6-7 minutes mid morning or mid afternoon in summer, and with as much bare skin exposed as feasible for 7-40 minutes (depending on latitude) at noon in winter, on most days, is likely to be helpful in maintaining adequate vitamin $D$ levels in the body

Vitamin $D$ intake required from dietary sources and supplementation to prevent deficiency

- At least $600 \mathrm{IU}(15 \mu \mathrm{g})$ per day for those aged $\leqslant 70$ years, and $800 \mathrm{IU}(20 \mu \mathrm{g})$ per day for those aged $>70$ years ${ }^{22}$

- Those in high-risk groups or with substantial sun avoidance may require higher doses

- Vitamin D supplementation of $1000 \mathrm{IU}(25 \mu \mathrm{g})$ per day, combined with adequate calcium intake, is required to reduce fracture risk in older people

Vitamin D supplementation required to treat moderate to severe deficiency

- 3000-5000 IU (75-125 $\mu \mathrm{g})$ per day for at least 6-12 weeks, with a check on 25-OHD concentrations for most people after 3 months, followed by ongoing treatment with a lower dose of around 1000-2000 IU per day (eg, 3-5 × $1000 \mathrm{IU}$ vitamin $D_{3}$ capsules per day or $0.6-1 \mathrm{~mL}$ of $5000 \mathrm{IU} / \mathrm{mL}$ liquid vitamin $D_{3}$ for $6-12$ weeks, followed by 1 capsule of $1000 \mathrm{IU}$ or $0.2 \mathrm{~mL}$ of $5000 \mathrm{IU} / \mathrm{mL}$ liquid per day) and adequate calcium intake

- An alternative is 50000 IU vitamin $D_{3}$ (eg, Calciferol Strong, API Consumer Brands, New Zealand only), 1 tablet, once per month for 3-6 months ${ }^{74 *}$

Most patients will need ongoing treatment with a lower dose (eg, $1000 \mathrm{IU}$ per day or equivalent)

* Monthly dosing is similarly effective and apparently safe but takes 3-5 months for plateau 25-OHD levels to be reached.

ing serum 25-OHD levels. As low calcium intake and associated hyperparathyroidism increase the degradation of vitamin D compounds, ${ }^{67,69,84}$ a daily intake of $1000-1300 \mathrm{mg}$ of calcium, preferably from calcium-rich foods, should be encouraged.

According to the best evidence currently available, adequate serum $25-\mathrm{OHD}$ levels of $\geqslant 50 \mathrm{nmol} / \mathrm{L}$ at the end of winter (10-20 nmol/L higher at the end of summer to allow for a seasonal decrease), along with recommended dietary calcium intakes and weight-bearing or muscle strengthening exercise, are required for optimal bone and muscle function, at least in older age groups. Although it is likely that serum 25-OHD levels that are somewhat higher than those required for musculoskeletal health play a small role in prevention of some disease states, there is evidence emerging of potential adverse effects of higher serum 25-OHD levels under some circumstances. RCTs to test these hypotheses need to be undertaken before higher targets can be recommended with confidence. 
Acknowledgements: We thank Dr Paul Glendenning and Professor Howard Morris for advice regarding most commonly used $25-\mathrm{OHD}$ assays and quality control issues in Australia, Dr Michael Ackland, Department of Health, Victoria, for advice regarding public health issues, and Associate Professor Craig Munns, Associate Professor Glyn Teale, Dr Georgia Paxton, Professor Philip Sambrook and Professor lan Reid for reviewing the final manuscript.

Competing interests: Rebecca Mason has received remuneration from Key Pharmaceuticals, Servier and the Australian Mushroom Growers' Association, and funding from Nestle. Caryl Nowson has received remuneration from Meat \& Livestock Australia. Peter Ebeling's department has received research funds from Sanofi-Aventis, and speaker fees from Merck and Sanofi-Aventis. Peter Ebeling and Kerrie Sander's department has also received research funding from Merck. These payments are unrelated to the submitted work.

Provenance: Not commissioned; externally peer reviewed.

1 Daly RM, Gagnon C, Lu ZX, et al. Prevalence of vitamin D deficiency and its determinants in Australian adults aged 25 years and older: a national, population-based study. Clin Endocrinol (Oxf) 2011; Dec 15 [Epub ahead of print]. doi: 10.1111/j.1365-2265.2011.04320.x.

2 Diamond TH, Eisman JA, Mason RS, et al. Vitamin D and adult bone health in Australia and New Zealand: a position statement. Med J Aust 2005; 182: 281285.

3 Deluca HF, Prahl JM, Plum LA. 1,25-Dihydroxyvitamin D is not responsible for toxicity caused by vitamin D or 25-hydroxyvitamin D. Arch Biochem Biophys 2011; 505: 226-230.

4 Holick MF. Vitamin D deficiency. N Engl J Med 2007; 357: 266-281.

5 Webb AR, Engelsen 0. Calculated ultraviolet exposure levels for a healthy vitamin D status. Photochem Photobiol 2006; 82: 1697-1703.

6 Rhodes LE, Webb AR, Fraser HI, et al. Recommended summer sunlight exposure levels can produce sufficient ( $\geqslant 20 \mathrm{ng} \mathrm{ml}^{-1}$ ) but not the proposed optimal $\geqslant 32 \mathrm{ng} \mathrm{ml}^{-1}$ ) 25(OH)D levels at UK latitudes. J Invest Dermatol 2010 130: 1411-1418.

7 Springbett P, Buglass S, Young AR. Photoprotection and vitamin D status. J Photochem Photobiol B 2010; 101: 160-168.

8 Gies P, Roy C, Javorniczky J, et al. Global Solar UV Index: Australian measurements, forecasts and comparison with the UK. Photochem Photobiol 2004; 79: 32-39.

9 Durvasula S, Kok C, Sambrook PN, et al. Sunlight and health: attitudes of older people living in intermediate care facilities in southern Australia. Arch Gerontol Geriatr 2010; 51: e94-e99.

10 van der Mei IA, Ponsonby AL, Dwyer T, et al. Vitamin D levels in people with multiple sclerosis and community controls in Tasmania, Australia. J Neurol 2007: 254: 581-590.

11 Glass D, Lens M, Swaminathan R, et al. Pigmentation and vitamin D metabolism in Caucasians: low vitamin D serum levels in fair skin types in the UK. PLoS One 2009; 4: e6477.

12 Wortsman J, Matsuoka LY, Chen TC, et al. Decreased bioavailability of vitamin D in obesity. Am J Clin Nutr 2000; 72: 690-693.

13 Holick MF. Vitamin D: the underappreciated D-lightful hormone that is important for skeletal and cellular health. Curr Opin Endocrinol Diabetes Obesity 2002; 9: 87-98.

14 Davie M, Lawson DE. Assessment of plasma 25-hydroxyvitamin D response to ultraviolet irradiation over a controlled area in young and elderly subjects. Clin Sci (Lond) 1980; 58: 235-242.

15 Grover SR, Morley R. Vitamin D deficiency in veiled or dark-skinned pregnant women. Med J Aust 2001; 175: 251-252.

16 Kimlin M, Harrison S, Nowak M, et al. Does a high UV environment ensure adequate vitamin D status? J Photochem Photobiol B 2007; 89: 139-147.

17 van der Mei IA, Ponsonby AL, Engelsen O, et al. The high prevalence of vitamin Dinsufficiency across Australian populations is only partly explained by season and latitude. Environ Health Perspect 2007; 115: 1132-1139.

18 Lucas RM, Ponsonby AL, Dear K, et al. Sun exposure and vitamin D are independent risk factors for CNS demyelination. Neurology 2011; 76: 540-548.

19 Nowson CA, Margerison C. Vitamin D intake and vitamin D status of Australians. Med J Aust 2002; 177: 149-152.

20 Whiting SJ, Langlois KA, Vatanparast H, Greene-Finestone LS. The vitamin D status of Canadians relative to the 2011 Dietary Reference Intakes: an examination in children and adults with and without supplement use. Am J Clin Nutr 2011; 94: 128-135.

21 National Health and Medical Research Council; New Zealand Ministry of Health. Nutrient reference values for Australia and New Zealand including recommended dietary intakes. Canberra: Commonwealth of Australia, 2006. http://www.nhmrc.gov.au/_files_nhmrc/publications/attachments/ n35.pdf?q=publications/synopses/_files/n35.pdf (accessed Nov 2011).

22 Institute of Medicine (US). Dietary reference intakes for calcium and vitamin D. Washington, DC: The National Acadamies Press, 2010. http://www.iom.edu/ Reports/2010/Dietary-Reference-Intakes-for-Calcium-and-Vitamin-D.aspx (accessed Mar 2012).

23 Malabanan A, Veronikis IE, Holick MF. Redefining vitamin D insufficiency. Lancet 1998; 351: 805-806.

24 Lips P, Bouillon R, van Schoor NM, et al. Reducing fracture risk with calcium and vitamin D. Clin Endocrinol (Oxf) 2010; 73: 277-285.
25 Bischoff-Ferrari HA, Dietrich T, Orav EJ, et al. Higher 25-hydroxyvitamin D concentrations are associated with better lower-extremity function in both active and inactive persons aged $>$ or $=60$ y. Am J Clin Nutr 2004; 80: 752-758.

26 Wicherts IS, van Schoor NM, Boeke AJ, et al. Vitamin D status predicts physical performance and its decline in older persons. J Clin Endocrinol Metab 2007; 92: 2058-2065.

27 Winzenberg T, Powell S, Shaw KA, Jones G. Effects of vitamin D supplementation on bone density in healthy children: systematic review and meta-analysis. BMJ 2011; 342: c7254.

28 Priemel M, von Domarus C, Klatte TO, et al. Bone mineralization defects and vitamin $\mathrm{D}$ deficiency: histomorphometric analysis of iliac crest bone biopsies and circulating 25-hydroxyvitamin D in 675 patients. J Bone Miner Res 2010; 25: 305-312.

29 Visser M, Deeg DJ, Lips P; Longitudinal Aging Study Amsterdam. Low vitamin D and high parathyroid hormone levels as determinants of loss of muscle strength and muscle mass (sarcopenia): the Longitudinal Aging Study Amsterdam. J Clin Endocrinol Metab 2003; 88: 5766-5772.

30 Bischoff-Ferrari HA, Dawson-Hughes B, Staehelin HB, et al. Fall prevention with supplemental and active forms of vitamin D: a meta-analysis of randomised controlled trials. BMJ 2009; 339: b3692.

31 Tang BM, Eslick GD, Nowson C, et al. Use of calcium or calcium in combination with vitamin $D$ supplementation to prevent fractures and bone loss in people aged 50 years and older: a meta-analysis. Lancet 2007; 370: 657-666.

32 Boonen S, Lips P, Bouillon R, et al. Need for additional calcium to reduce the risk of hip fracture with vitamin d supplementation: evidence from a comparative metaanalysis of randomized controlled trials. J Clin Endocrinol Metab 2007; 92: 1415-1423.

33 DIPART (Vitamin D Individual Patient Analysis of Randomized Trials) Group. Patient level pooled analysis of 68500 patients from seven major vitamin D fracture trials in US and Europe. BMJ 2010; 340: b5463.

34 Avenell A, Gillespie WJ, Gillespie LD, O'Connell D. Vitamin D and vitamin D analogues for preventing fractures associated with involutional and postmenopausal osteoporosis. Cochrane Database Syst Rev 2009; (2): CD000227.

35 Ross AC, Manson JE, Abrams SA, et al. The 2011 report on dietary reference intakes for calcium and vitamin D from the Institute of Medicine: what clinicians need to know. J Clin Endocrinol Metab 2011; 96: 53-58.

36 Hyppönen E, Läärä E, Reunanen A, et al. Intake of vitamin D and risk of type 1 diabetes: a birth-cohort study. Lancet 2001; 358: 1500-1503.

37 Souberbielle JC, Body JJ, Lappe JM, et al. Vitamin D and musculoskeletal health, cardiovascular disease, autoimmunity and cancer: Recommendations for clinical practice. Autoimmun Rev 2010; 9: 709-715.

38 Wang TJ, Pencina MJ, Booth SL, et al. Vitamin D deficiency and risk of cardiovascular disease. Circulation 2008; 117: 503-511.

39 von Hurst PR, Stonehouse W, Coad J. Vitamin D supplementation reduces insulin resistance in South Asian women living in New Zealand who are insulin resistant and vitamin D deficient - a randomised, placebo-controlled trial. $\mathrm{Br} J$ Nutr 2010; 103: 549-555.

40 Pittas AG, Lau J, Hu FB, Dawson-Hughes B. The role of vitamin D and calcium in type 2 diabetes. A systematic review and meta-analysis. J Clin Endocrinol Metab 2007; 92: 2017-2029.

41 Lappe JM, Travers-Gustafson D, Davies KM, et al. Vitamin D and calcium supplementation reduces cancer risk: results of a randomized trial. Am J Clin Nutr 2007; 85: 1586-1591.

42 Gandini S, Boniol M, Haukka J, et al. Meta-analysis of observational studies of serum 25-hydroxyvitamin D levels and colorectal, breast and prostate cancer and colorectal adenoma. Int J Cancer 2011; 128: 1414-1424.

43 Nnoaham KE, Clarke A. Low serum vitamin D levels and tuberculosis: a systematic review and meta-analysis. Int J Epidemiol 2008; 37: 113-119.

44 Urashima M, Segawa T, Okazaki M, et al. Randomized trial of vitamin D supplementation to prevent seasonal influenza A in schoolchildren. Am J Clin Nutr 2010; 91: 1255-1260.

45 Yamshchikov AV, Desai NS, Blumberg HM, et al. Vitamin D for treatment and prevention of infectious diseases: a systematic review of randomized controlled trials. Endocr Pract 2009; 15: 438-449.

46 Buell JS, Scott TM, Dawson-Hughes B, et al. Vitamin D is associated with cognitive function in elders receiving home health services. J Gerontol A Biol Sci Med Sci 2009; 64: 888-895.

47 Knekt P, Kilkkinen A, Rissanen H, et al. Serum vitamin D and the risk of Parkinson disease. Arch Neurol 2010; 67: 808-811.

48 Milaneschi Y, Shardell M, Corsi AM, et al. Serum 25-hydroxyvitamin D and depressive symptoms in older women and men. J Clin Endocrinol Metab 2010; 95: 3225-3233.

49 McGrath JJ, Eyles DW, Pedersen CB, et al. Neonatal vitamin D status and risk of schizophrenia: a population-based case-control study. Arch Gen Psychiatry 2010; 67: 889-894.

50 Melamed ML, Michos ED, Post W, Astor B. 25-hydroxyvitamin D levels and the risk of mortality in the general population. Arch Intern Med 2008; 168: 16291637.

51 Autier P, Gandini S. Vitamin D supplementation and total mortality: a metaanalysis of randomized controlled trials. Arch Intern Med 2007; 167: 1730-1737. 
52 Latham NK, Anderson CS, Reid IR. Effects of vitamin D supplementation on strength, physical performance, and falls in older persons: a systematic review. J Am Geriatr Soc 2003; 51: 1219-1226.

53 Merlino LA, Curtis J, Mikuls TR, et al. Vitamin D intake is inversely associated with rheumatoid arthritis: results from the lowa Women's Health Study. Arthritis Rheum 2004; 50: 72-77.

54 Melamed ML, Muntner P, Michos ED, et al. Serum 25-hydroxyvitamin D levels and the prevalence of peripheral arterial disease: results from NHANES 2001 to 2004. Arterioscler Thromb Vasc Biol 2008; 28:1179-1185.

55 National Health and Medical Research Council. NHMRC levels of evidence and grades for recommendations for developers of guidelines. Canberra: NHMRC, 2009. http://www.nhmrc.gov.au/files_nhmrc/file/guidelines/evidence_ statement_form.pdf (accessed Mar 2012).

56 Heaney RP, Holick MF. Why the IOM recommendations for vitamin D are deficient. J Bone Miner Res 2011; 26: 455-457.

57 Ginde AA, Scragg R, Schwartz RS, Camargo CA Jr. Prospective study of serum 25-hydroxyvitamin D level, cardiovascular disease mortality, and all-cause mortality in older US adults. J Am Geriatr Soc 2009; 57: 1595-1603.

58 Michaëlsson K, Baron JA, Snellman G, et al. Plasma vitamin D and mortality in older men: a community-based prospective cohort study. Am J Clin Nutr 2010; 92: 841-848.

59 Tuohimaa P, Tenkanen L, Ahonen M, et al. Both high and low levels of blood vitamin $D$ are associated with a higher prostate cancer risk: a longitudinal, nested case-control study in the Nordic countries. Int J Cancer 2004; 108: 104108.

60 Ensrud KE, Ewing SK, Fredman L, et al; Study of Osteoporotic Fractures Research Group. Circulating 25-hydroxyvitamin D levels and frailty status in older women. J Clin Endocrinol Metab 2010; 95: 5266-5273.

61 Ahn J, Yu K, Stolzenberg-Solomon R, et al. Genome-wide association study of circulating vitamin D levels. Hum Mol Genet 2010; 19: 2739-2745.

62 Giovannucci E, Liu Y, Rimm EB, et al. Prospective study of predictors of vitamin D status and cancer incidence and mortality in men. J Natl Cancer Inst 2006; 98: 451-459.

63 Scragg R, Holdaway I, Jackson R, Lim T. Plasma 25-hydroxyvitamin D3 and its relation to physical activity and other heart disease risk factors in the general population. Ann Epidemiol 1992; 2: 697-703.

64 Wang TJ, Zhang F, Richards JB, et al. Common genetic determinants of vitamin D insufficiency: a genome-wide association study. Lancet 2010; 376: 180-188.

65 Clements MR, Davies M, Fraser DR, et al. Metabolic inactivation of vitamin D is enhanced in primary hyperparathyroidism. Clin Sci (Lond) 1987; 73: 659-664.

66 Christiansen C, Rodbro P, Lund M. Incidence of anticonvulsant osteomalacia and effect of vitamin D: controlled therapeutic trial. BMJ 1973; 4: 695-701.

67 Clements MR, Johnson L, Fraser DR. A new mechanism for induced vitamin D deficiency in calcium deprivation. Nature 1987; 325: 62-65.

68 Berlin T, Björkhem I. Effect of calcium intake on serum levels of 25hydroxyvitamin D3. Eur J Clin Invest 1988; 18: 52-55.
69 Davies M, Heys SE, Selby PL, et al. Increased catabolism of 25-hydroxyvitamin $D$ in patients with partial gastrectomy and elevated 1,25-dihydroxyvitamin D levels. Implications for metabolic bone disease. J Clin Endocrinol Metab 1997; 82: 209-212

70 Clements MR, Chalmers TM, Fraser DR. Enterohepatic circulation of vitamin D: a reappraisal of the hypothesis. Lancet 1984; 1:1376-1379.

71 Vieth R. Vitamin D supplementation, 25-hydroxyvitamin D concentrations, and safety. Am J Clin Nutr 1999; 69: 842-856.

72 Vieth R, Chan PC, MacFarlane GD. Efficacy and safety of vitamin D3 intake exceeding the lowest observed adverse effect level. Am J Clin Nutr 2001; 73 : 288-294.

73 Heaney RP, Davies KM, Chen TC, et al. Human serum 25-hydroxycholecalciferol response to extended oral dosing with cholecalciferol. Am J Clin Nutr 2003; 77: 204-210.

74 Bacon CJ, Gamble GD, Horne AM, et al. High-dose oral vitamin D3 supplementation in the elderly. Osteoporos Int 2009; 20: 1407-1415.

75 Sanders KM, Stuart AL, Williamson EJ, et al. Annual high-dose oral vitamin D and falls and fractures in older women: a randomized controlled trial. JAMA 2010; 303: 1815-1822.

76 Trivedi DP, Doll R, Khaw KT. Effect of four monthly oral vitamin D3 (cholecalciferol) supplementation on fractures and mortality in men and women living in the community: randomised double blind controlled trial. BMJ 2003; 326: 469.

77 Horwitz MJ. What medical options should be considered for the treatment of primary hyperparathyroidism? Clin Endocrinol (Oxf) 2011; 75: 592-595.

78 Henry HL, Bouillon R, Norman AW, et al. 14th Vitamin D Workshop consensus on vitamin D nutritional guidelines. J Steroid Biochem Mol Biol 2010; 121: 4-6.

79 Wallace AM Gibson S, de la Hunty A, et al. Measurement of 25-hydroxyvitamin $D$ in the clinical laboratory: current procedures, performance characteristics and limitations. Steroids 2010; 75: 477-488.

80 Aloia JF, Patel M, Dimaano R, et al. Vitamin D intake to attain a desired serum 25-hydroxyvitamin D concentration. Am J Clin Nutr 2008; 87: 1952-1958.

81 Harris SS, Dawson-Hughes B. Plasma vitamin D and 250HD responses of young and old men to supplementation with vitamin D3. J Am Coll Nutr 2002; 21: 357-362.

82 Bacon CJ, Woo J, Lau EM, et al. Effects of 25-hydroxyvitamin D level and its change on parathyroid hormone in premenopausal Chinese women. Osteoporos Int 2010; 21: 1935-1941.

83 Ish-Shalom S, Segal E, Salganik T, et al. Comparison of daily, weekly, and monthly vitamin D3 in ethanol dosing protocols for two months in elderly hip fracture patients. J Clin Endocrinol Metab 2008; 93: 3430-3435.

84 Holick MF, Biancuzzo RM, Chen TC, et al. Vitamin D2 is as effective as vitamin D3 in maintaining circulating concentrations of 25-hydroxyvitamin D. J Clin Endocrinol Metab 2008; 93: 677-681.

85 Heaney RP, Recker RR, Grote J, et al. Vitamin D(3) is more potent than vitamin $\mathrm{D}(2)$ in humans. J Clin Endocrinol Metab 2011; 96: E447-E452. 